\title{
Poly(ethylene glycol) Methyl Ether Methacrylate-bonded Stationary Phase in Ion Chromatography and Its Application to Seawater Samples
}

\author{
Li Rong, ${ }^{*}, * *$ Lee Wah LIM, ${ }^{* * \dagger}$ and Toyohide TAKEUCHI** \\ *Department of Chemistry, School of Science, Xihua University, 999 Jinzhou-Road, Chengdu 610039, China \\ **Department of Chemistry and Biomolecular Science, Faculty of Engineering, Gifu University, 1-1 Yanagido, \\ Gifu 501-1193, Japan
}

\begin{abstract}
A fast and simple ion chromatographic method for the determination of iodide in seawater is reported using poly(ethylene glycol) methyl ether methacrylate-bonded stationary phase. Poly(ethylene glycol) methyl ether methacrylate was reacted with primary amino groups of aminopropylsilica in $N, N$-dimethylformamide at $80^{\circ} \mathrm{C}$. The prepared stationary phases were evaluated by analyzing several inorganic anions and the retention behavior was observed. Various chromatographic parameters were optimized for the separation of these anions. Although there were no ion-exchange sites on the resulted stationary phases, the results obtained suggested that an ion-exchange mechanism was involved in the retention of analyte anions. With $0.15 \mu \mathrm{L}$ injection, the limit of quantitation of iodide was $26 \mu \mathrm{g} \mathrm{L}^{-1}$ when $200 \mathrm{mM} \mathrm{NaCl}$ was selected as the eluent. This stationary phase was applied to the analysis of direct and fast determination of iodide in real seawater samples successfully with the recovery rates of 98.1 and $104.9 \%$.
\end{abstract}

Keywords Ion chromatography, poly(ethylene glycol) methyl ether methacrylate-bonded stationary phase, iodide, seawater

(Received October 12, 2020; Accepted December 4, 2020; Advance Publication Released Online by J-STAGE December 11, 2020)

\section{Introduction}

Since it was introduced in 1975 by Small et al., ${ }^{1}$ ion chromatography (IC) has been used as a routine method to separate inorganic cations ${ }^{2-4}$ and anions, ${ }^{2-6}$ and/or small organic ions ${ }^{3,7}$ in aqueous samples. Until now, various types of stationary phases have been developed in IC, and most stationary phases have functional groups with charged or chargeable moieties, where analyte ions undergo an electrostatic attraction and/or repulsion. Among IC columns, silica-gel is an ideal support due to its favorable characteristics, such as high chemical and thermal stability, good mechanical strength, controllable surface area and pore structure, surface rich in silanol groups, and so on..$^{8,9}$

Poly(ethylene glycol) (PEG), also called as polyoxyethylene (POE) or polyethylene oxide (PEO), is a polymer compound with repeating units of ethylene oxide $\left(\mathrm{H}-\left[\mathrm{O}-\mathrm{CH}_{2}-\mathrm{CH}_{2}\right] \mathrm{n}-\mathrm{OH}\right)$, and it has a number of properties that makes it attractive to biotechnological and biomedical applications including phase partitioning, non-fouling surfaces and peptide and protein modification. PEG is used in IC, ${ }^{10-13}$ countercurrent chromatography (CCC), ${ }^{14,15}$ capillary gas chromatography (CGC), ${ }^{16,17}$ and liquid chromatography (LC) ${ }^{18,19}$ as the stationary phase. In addition to hydrophobic interaction, PEG can also provide dipole-dipole interaction, hydrogen bonding and other interactions. Moreover, in organic medium the PEG moieties could enable a spiral structure. ${ }^{20}$

$\dagger$ To whom correspondence should be addressed.

E-mail: lim@gifu-u.ac.jp
We developed and examined PEG and POE as the stationary phase for the separation of inorganic anions in IC. ${ }^{10-13}$ Chemicalbonded ${ }^{13}$ and/or physical-coated PEG $^{10-12}$ stationary phases have been reported, and retention behaviors were investigated. The experimental results showed that the retention of analyte anions increased with the increase of eluent concentration, and the retention of analyte anions on the PEG and/or POE stationary phases were influenced by both eluent cations and anions. It was suggested that inorganic anions, interacted with eluent cation, distributed into the PEG and/or POE stationary phase, and the hydration strength of eluent cations and anions might affect the hydrophobicity of the stationary phase. These PEG and/or POE stationary phases have been successfully applied for the iodide determination in real samples. However, the physicalcoated PEG stationary phases could only be used for a few weeks, because the PEG modifier was gradually flushed away by the eluent during the experiment. On the other hand, the chemical-bonded PEG stationary phases are not sensitive enough for the determination of trace iodide contained in most seawater samples.

Therefore, the aim of the present study is to develop a new chemical-bonded PEG stationary phase for the determination of iodide in seawater samples with long-term stability and high sensitivity. A new PEGylation reagent for the preparation of stationary phases in IC was examined. Poly(ethylene glycol) methyl ether methacrylate was reacted with aminopropylsilica for the separation of inorganic anions with better detection sensitivity. Then the optimized IC system was applied for the direct and fast determination of iodide in seawater samples without any pretreatment of samples. 

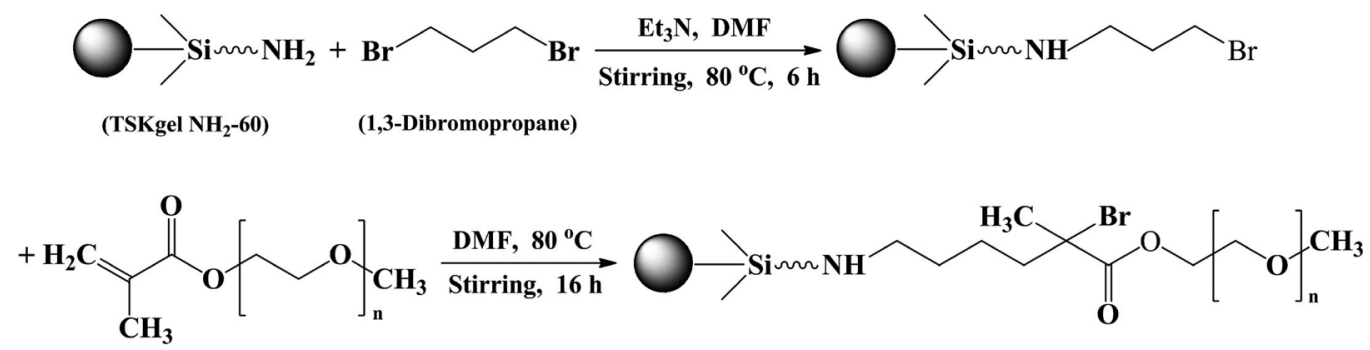

(Poly(ethylene glycol) methyl ether methacrylate)

(PEGMEMA/TSKgel NH $\left.\mathrm{N}_{2}-60\right)$

Fig. 1 Expected reaction between TSKgel $\mathrm{NH}_{2}-60$ and PEGMEMA.

\section{Experimental}

Apparatus

The IC system used in the present study was composed of an eluent delivery pump (L.TEX-8301 Micro Feeder, L.TEX Corporation, Tokyo, Japan, with an $0.5 \mathrm{~mL}$ MS-GAN 050 gastight syringe, Ito, Fuji, Japan), a Model M435 micro injection valve with $0.15 \mu \mathrm{L}$ sample loop (Upchurch Scientific, Oak Harbor, WA, USA), a UV-970 UV detector (with a $75 \mu \mathrm{m}$ capillary flow cell, JASCO, Tokyo, Japan) and a CDS data processor (LAsoft, Chiba, Japan). An L.TEX-8150 Pressure Sensor (L.TEX) was used to monitor the inlet pressure. A Model 5220 centrifuge (Kubota, Tokyo, Japan) was used to wash the reaction products.

\section{Reagents}

Reagents were guaranteed reagent grade and were obtained from Tokyo Chemical Industry Co., Ltd (Tokyo, Japan), Wako Pure Chemical Industries (Osaka, Japan), or Nacalai Tesuque (Kyoto, Japan), unless otherwise indicated. Poly(ethylene glycol) methyl ether methacrylate (PEGMEMA, average M.W. 500) was obtained from Sigma-Aldrich Co. LLC (St. Louis, MO, USA). Purified water was produced in the laboratory by using a simplicity UV water purification system (Merck Millipore, Darmstadt, Germany). After preparation with the use of the purified water, all solutions were filtered by using a $0.45 \mu \mathrm{m}$ membrane filter (GL ChromatoDisk, GL Sciences Inc., Tokyo, Japan) and stored at $4^{\circ} \mathrm{C}$ in a refrigerator before use. Porous 3-aminopropylsilica, i.e. TSKgel $\mathrm{NH}_{2}-60 \quad(5 \mu \mathrm{m}$ particle diameter, $60 \AA$ mean pore diameter) was taken from a packed column supplied from TOSOH (Tokyo, Japan).

\section{Column preparation}

In order to bond the PEGylation reagent, i.e. PEGMEMA, onto the silica gel, TSKgel $\mathrm{NH}_{2}-60$ was selected as the base stationary phase. A $0.05 \mathrm{~g}$ of TSKgel $\mathrm{NH}_{2}-60,0.1 \mathrm{~mL}$ 1,3-dibromopropane, $0.02 \mathrm{~mL}$ triethylamine $\left(\mathrm{Et}_{3} \mathrm{~N}\right)$, and $2 \mathrm{~mL}$ $\mathrm{N}, \mathrm{N}$-dimethylformamide (DMF) were added into a $3-\mathrm{mL}$ vial. The reaction was carried out for $6 \mathrm{~h}$ at $80^{\circ} \mathrm{C}$ while stirring slowly. After washig with methanol, the silica gel was reacted with $0.1 \mathrm{~mL}$ PEGMEMA using $2 \mathrm{~mL}$ DMF as the solvent, and then the reaction was carried out for $16 \mathrm{~h}$ at $80^{\circ} \mathrm{C}$ while stirring slowly. The expected reaction scheme is shown in Fig. 1. After centrifugation and washing with methanol and purified water repeatedly, the PEGMEMA/TSKgel $\mathrm{NH}_{2}-60$ silica gel was packed into a fused-silica capillary tube with $0.32 \mathrm{~mm}$ i.d. by using a slurry packing method previously reported, ${ }^{21}$ and then conditioned with purified water and eluent until the baseline was stabilized. All columns were controlled at room temperature (ca. $\left.25^{\circ} \mathrm{C}\right)$.

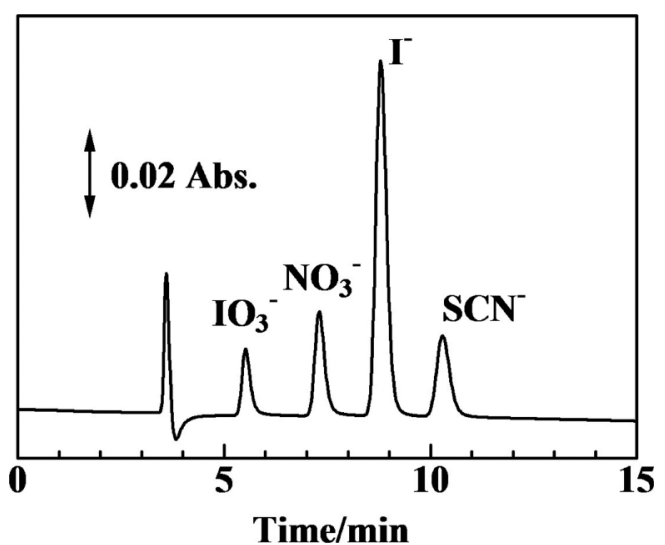

Fig. 2 Separation of authentic mixture of UV-absorbing anions on the PEGMEMA/TSKgel $\mathrm{NH}_{2}-60$ stationary phase. Column, PEGMEMA/TSKgel $\mathrm{NH}_{2}-60$ packed column $(100 \times 0.32 \mathrm{~mm}$ i.d. $)$; eluent, $200 \mathrm{mM}$ sodium chloride; flow-rate, $2.0 \mu \mathrm{L} \mathrm{min}{ }^{-1}$; injection volume, $0.15 \mu \mathrm{L}$; analyte, $0.2 \mathrm{mM}$ each of iodate, nitrate, iodide, and thiocyanate; wavelength of UV detection, $225 \mathrm{~nm}$.

\section{Real sample analysis}

The seawater samples were collected from Centrair airport $\left(\mathrm{N} 34^{\circ} 89^{\prime}, \mathrm{E} 136^{\circ} 82^{\prime}\right)$ and Shinmaiko port $\left(\mathrm{N} 34^{\circ} 95^{\prime}, \mathrm{E} 136^{\circ} 82^{\prime}\right)$ in Aichi Prefecture, Japan, and used in this developed method within a few days after the sampling. The seawater samples were filtered by using a $0.45 \mu \mathrm{m}$ membrane filter, then injected directly to the present IC system.

\section{Results and Discussion}

Retention of anions on PEGMEMA/TSKgel $\mathrm{NH}_{2}-60$ stationary phase

Due to the reaction of aminopropyl silica with PEGMEMA, compared to unmodified TSKgel $\mathrm{NH}_{2}-60$, the prepared PEGMEMA/TSKgel $\mathrm{NH}_{2}-60$ chemical-bonded stationary phase improved the column selectivity and retained inorganic anions more strongly. The aim of the present study is to determine trace iodide in seawater, since its distribution provides important clues about the marine environment. Therefore, UV-absorbing inorganic anions such as iodate $\left(\mathrm{IO}_{3}^{-}\right)$, nitrate $\left(\mathrm{NO}_{3}^{-}\right)$, iodide $\left(\mathrm{I}^{-}\right)$ and thiocyanate $\left(\mathrm{SCN}^{-}\right)$were selected as the analyte anions. Figure 2 shows the separation of these four inorganic anions on the PEGMEMA/TSKgel $\mathrm{NH}_{2}-60$ column using $200 \mathrm{mM} \mathrm{NaCl}$ eluent. The retention times of these four inorganic anions increased in the order: $\mathrm{IO}_{3}^{-}<\mathrm{NO}_{3}^{-}<\mathrm{I}^{-}<\mathrm{SCN}^{-}$, and this was 


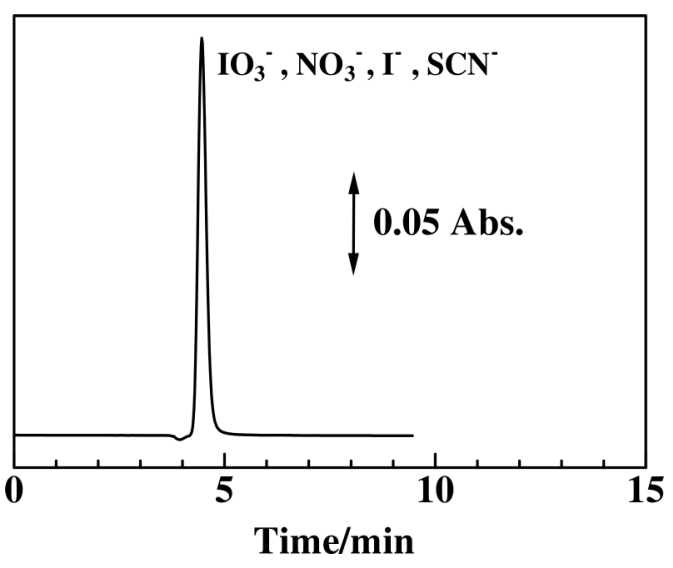

Fig. 3 Separation of authentic mixture of UV-absorbing anions on the unmodified TSKgel $\mathrm{NH}_{2}-60$ stationary phase. Column, unmodified TSKgel $\mathrm{NH}_{2}-60$ packed column $(100 \times 0.32 \mathrm{~mm}$ i.d. $)$; other operating conditions as in Fig. 2.

similar to that observed on common anion exchangers employed in IC. It was also shown that the column selectivity is satisfactory, and the separation was completed within an appropriate time.

On the other hand, on the unmodified TSKgel $\mathrm{NH}_{2}-60$ stationary phase, the selectivity of the four inorganic anions was poor, and the retention of these four anions was much weaker than that on the chemical-bonded stationary phase. For example, on a $0.32 \mathrm{~mm}$ i.d. $\times 100 \mathrm{~mm}$ unmodified TSKgel $\mathrm{NH}_{2}-60$ column (the experimental conditions were the same as in Fig. 2) $\mathrm{IO}_{3}^{-}, \mathrm{NO}_{3}^{-}, \mathrm{I}^{-}$, and $\mathrm{SCN}^{-}$were eluted at 4.442, 4.450, 4.451, and 4.463 min respectively, and could not be separated, as shown in Fig. 3. It was shown that when chemically bonded with PEGMEMA, the retention of the analyte anions increased and it improved the separation selectivity of all these monovalent anions due to the eluent-induced ion interaction effect.

\section{Retention behaviors of anions}

Interaction between stationary phase and eluent may have an influence on the retention and selectivity in IC. Since the concentration of eluent is one of the most important parameters, influences of the eluent concentration on the iodide retention were evaluated when lithium chloride $(\mathrm{LiCl})$, sodium chloride $(\mathrm{NaCl})$, potassium chloride $(\mathrm{KCl})$, and sodium sulfate $\left(\mathrm{Na}_{2} \mathrm{SO}_{4}\right)$ were selected as the eluent. The effect of eluent concentration on the retention factor of iodide is demonstrated in Fig. 4. It can be seen that the retention of iodide ion decreased when eluents concentration was increased in the region between 50 and $200 \mathrm{mM}$. And there was a good linear relationship between the logarithm of iodide retention factor $(\log k)$ and the logarithm of eluent concentration. The slopes of $\mathrm{LiCl}, \mathrm{NaCl}, \mathrm{KCl}$, and $\mathrm{Na}_{2} \mathrm{SO}_{4}$ were $-0.985,-0.936,-0.936$, and -0.422 , respectively, which were in good agreement with the theoretical slopes of -1.0 and -0.5 for chloride ion and sulfate ion. The retention of anions on the present chemical-bonded stationary phase was suggested to be based on an ion-exchange mechanism. In spite of the fact that the PEGMEMA/TSKgel $\mathrm{NH}_{2}-60$ stationary phase possesses no ion exchange sites, anions are expected to be retained in the ion-exchange mode. The separation of anions was supposed to be based on capturing the eluent cations, which coordinated the oxygen atoms of the PEGMEMA moieties by ion-dipole interaction functioning as the anion-exchange sites. In addition, $\mathrm{Li}^{+}, \mathrm{Na}^{+}$, and $\mathrm{K}^{+}$as the eluent cation had a tendency

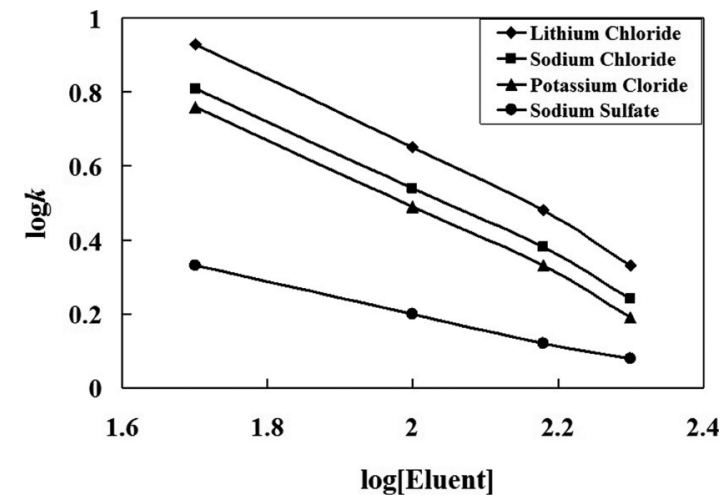

Fig. 4 Effect of eluent concentration on the retention of iodide ion. Eluent concentration, as indicated; other operating conditions as in Fig. 2.

to achieve larger retention factor values for iodide in this order when strongly hydrated anion, viz. $\mathrm{Cl}^{-}$, was selected as the eluent anion. The eluent cation also could affect the retention of analyte anions. When $\mathrm{NaCl}$ was selected as the eluent, better resolution, i.e., better peak shape was achieved. Considering the resolution and the retention time of analyte anions, $200 \mathrm{mM}$ $\mathrm{NaCl}$ was selected as the eluent. And the highest theoretical plate number (1530/column) was obtained.

The ion-exchange capacity of the PEGMEMA/TSKgel $\mathrm{NH}_{2}-$ 60 stationary phase was determined using the breakthrough curve. Briefly, the PEGMEMA/TSKgel $\mathrm{NH}_{2}-60$ stationary phase was equilibrated with $0.5 \mathrm{mM} \quad \mathrm{Na}_{2} \mathrm{SO}_{4}$ and then equilibrated with purified water until the baseline was stabilized, finally equilibrated with $1 \mathrm{mM} \mathrm{NaIO}, \mathrm{NaNO}_{3}, \mathrm{NaI}$ and/or NaSCN eluent at $2.0 \mu \mathrm{L} \mathrm{min}^{-1}$ until the breakthrough was achieved, and at the same time the effluent was monitored by UV-970 UV detector operated at $210 \mathrm{~nm}$. The breakthrough finished in $c a .13 .6 \mathrm{~min}$ for all of the eluent, while the $t_{0}$ was $3.6 \mathrm{~min}$. So, the ion exchange capacity of the PEGMEMA/ TSKgel $\mathrm{NH}_{2}-60$ stationary phase was calculated as $2 \times 10^{-8}$ eq column ${ }^{-1}$.

\section{Validation}

The repeatability of the retention time and signal intensity for six consecutive chromatographic runs are given in Table 1 . The relative standard deviations (RSDs, $n=6$ ) were smaller than $4.69 \%$ for the retention time, peak area and peak height. These values show that the present system has good stability and is acceptable for the determination of these anions.

In addition, with $0.15 \mu \mathrm{L}$ injection, the limit of detection (LOD) of iodide was $8 \mu \mathrm{g} \mathrm{L}-1 \quad(S / N=3)$, and the limit of quantification (LOQ) was $26 \mu \mathrm{g} \mathrm{L}^{-1}(S / N=10)$ when $200 \mathrm{mM}$ $\mathrm{NaCl}$ was selected as the eluent. These results indicate that this IC system obtained 2 times higher detection sensitivity than our previous study. ${ }^{13}$ Moreover, the quantitative linear range of iodide was $26 \mu \mathrm{g} \mathrm{L}^{-1}-63 \mathrm{mg} \mathrm{L}{ }^{-1}$ with the regression coefficient $\left(r^{2}\right)$ of 0.9998 .

\section{Application to seawater}

Determination of trace ions with bulk matrix ions is one of the most difficult applications by IC. Therefore, seawater samples were applied in this developed method. A peak due to iodide ion was observed for the seawater, as shown in Fig. 5. Although the seawater samples contained chloride and sulfate with molar concentrations that were much higher than the eluent 
Table 1 Repeatability for test analyte anions

\begin{tabular}{|c|c|c|c|c|c|c|}
\hline & \multicolumn{3}{|c|}{$\operatorname{RSD}(\%, n=6$, within-day) } & \multicolumn{3}{|c|}{$\operatorname{RSD}(\%, n=6$, day-to-day) } \\
\hline & $\begin{array}{l}\text { Retention } \\
\text { time }\end{array}$ & $\begin{array}{l}\text { Peak } \\
\text { area }\end{array}$ & $\begin{array}{c}\text { Peak } \\
\text { height }\end{array}$ & $\begin{array}{l}\text { Retention } \\
\text { time }\end{array}$ & $\begin{array}{l}\text { Peak } \\
\text { area }\end{array}$ & $\begin{array}{l}\text { Peak } \\
\text { height }\end{array}$ \\
\hline $\mathrm{IO}_{3}^{-}$ & 0.46 & 3.11 & 2.87 & 1.35 & 4.69 & 3.20 \\
\hline $\mathrm{NO}_{3}^{-}$ & 0.51 & 3.27 & 2.75 & 1.46 & 3.50 & 3.14 \\
\hline $\mathrm{I}^{-}$ & 0.50 & 3.08 & 2.44 & 1.22 & 3.02 & 2.92 \\
\hline $\mathrm{SCN}^{-}$ & 0.58 & 3.34 & 1.63 & 1.31 & 3.87 & 1.90 \\
\hline
\end{tabular}

Column, PEGMEMA/TSKgel NH${ }_{2}-60$ packed column $(100 \times 0.32 \mathrm{~mm}$ i.d.); analyte, $0.2 \mathrm{mM}$ each of iodate, nitrate, iodide, and thiocyanate; other operating conditions as in Fig. 2.

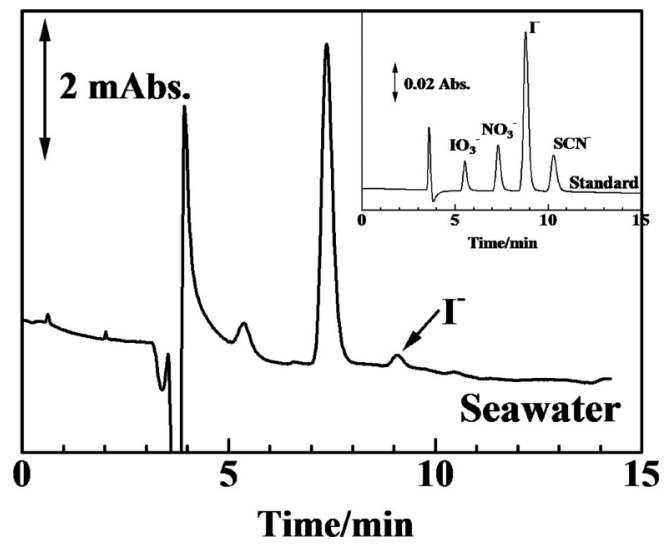

Fig. 5 Typical chromatograms of seawater and an authentic mixture of inorganic anions on the PEGMEMA/TSKgel $\mathrm{NH}_{2}-60$ stationary phase. Operating conditions as in Fig. 2.

concentration of chloride, the retention of these anions was very small and had no effect on the determination of iodide ion. A large peak before $\mathrm{I}^{-}$was considered to be the peak of $\mathrm{Br}^{-}$, $\mathrm{NO}_{3}{ }^{-}$and $\mathrm{NO}_{2}{ }^{-}$contained in seawater.

By using the standard addition method, $\mathrm{I}^{-}$contained in the seawater samples could be determined to be 45 and $32 \mu \mathrm{g} \mathrm{L}^{-1}$ for Centrair and Shinmaiko seawater, respectively. The recoveries of added iodide were 98.1 and $104.9 \%$ for the spiked seawater samples, as shown in Table 2.

\section{Conclusions}

This robust PEGMEMA/TSKgel $\mathrm{NH}_{2}-60$ stationary phase was successfully applied to separate inorganic anions. And it was applicable for the direct determination of trace iodide in seawater, with long-term stability and high sensitivity, to avoid adding matrix ions at very high concentrations to the eluent. Direct and fast determination of iodide was achieved successively within $10 \mathrm{~min}$ without any sample pretreatment, except filtering.
Table 2 Iodide concentration and recovery in seawater samples

\begin{tabular}{cccc}
\hline Seawater sample & Found $/ \mu \mathrm{g} \mathrm{L}^{-1}$ & Spiked/ $\mu \mathrm{g} \mathrm{L}^{-1}$ & Recovery, \% \\
\hline Centrair & 45 & 50 & 98.1 \\
Shinmaiko & 32 & 50 & 104.9 \\
\hline
\end{tabular}

Operating conditions as in Fig. 2.

\section{Acknowledgements}

This work was a project sponsored by the Technology Foundation for Selected Overseas Chinese, Sichuan Provincial Human Resources and Social Security Department (No. 4233474). The authors also would like to thank TOSOH Corporation, Tokyo, Japan, for their kindness in supplying of the TSKgel $\mathrm{NH}_{2}-60$ stationary phase.

\section{References}

1. H. Small, T. S. Stevens, and W. C. Bauman, Anal. Chem., 1975, 47, 1801.

2. S. Yoshii, M. Mori, D. Kozaki, T. Hosokawa, and H. Itabashi, Anal. Sci., 2019, 35, 1117.

3. L. Cao, X. Li, L. Fan, L. Zheng, M. Wu, S. Zhang, and Q. Huang, Mar. Drugs, 2017, 15, 51.

4. T. Umemura, Chromatography, 2019, 40, 143.

5. F. Akter, S. Saito, Y. Tasaki-Handa, and M. Shibukawa, Anal. Sci., 2018, 34, 369.

6. K. Tsuge, L. W. Lim, and T. Takeuchi, Anal. Sci., 2021, 37, 845.

7. I. Ueta, M. Kahimoto, and Y. Saito, Chromatography, 2019, 40, 33.

8. T. Takeuchi, J. Chromatogr. A, 1997, 780, 219.

9. X. Yang, J. Wang, and B. Xiong, Chin. J. Chromatogr., 2000, 18, 308.

10. L. Rong and T. Takeuchi, J. Chromatogr. A, 2004, 1042, 131.

11. L. Rong, L. W. Lim, and T. Takeuchi, Chromatographia, 2005, 61, 371 .

12. L. Rong, L. W. Lim, and T. Takeuchi, Talanta, 2007, 72, 1625.

13. L. Rong, L. W. Lim, and T. Takeuchi, J. Chromatogr. A, 2006, $1128,68$.

14. Y. Ito, T. Clary, J. Powell, M. Knight, and T. M. Finn, J. Chromatogr. A, 2009, 1216, 4193.

15. Y. Yang, Y. Zhang, C. Liu, Z. Jia, Y. Yin, T. Chu, and Y. Ito, J. Chromatogr. B, 2018, 1100, 39.

16. C. Shende, A. Kabir, E. Townsend, and A. Malik, Anal. Chem., 2003, 75, 3518.

17. T. Sun, X. Shuai, K. Ren, X. Jiang, Y. Chen, X. Zhao, Q. Song, S. Hu, and Z. Cai, Molecules, 2019, 24, 3158.

18. Z. Guo, Y. Liu, J. Xu, Q. Xu, X. Xue, F. Zhang, Y. Ke, X. Liang, and A. Lei, J. Chromatogr. A, 2008, 1191, 78.

19. A. Rahayu, L. W. Lim, and T. Takeuchi, Talanta, 2015, 34, 232.

20. L. W. Lim, L. Rong, and T. Takeuchi, Anal. Sci., 2012, 28, 205.

21. T. Takeuchi and D. Ishii, J. Chromatogr., 1981, 213, 25. 